\title{
The digital disruption of productivity
}

Written by: Diane Coyle, Professor of Economics, University of Manchester and Fellow, Office for National Statistics

Last update: 26 May 2016

The UK's tallest mountain is Ben Nevis in Scotland. Recently, it became one metre taller, standing now at $1345 \mathrm{~m}$ rather than 1 $344 \mathrm{~m}$ above sea level. Of course, the mountain did not actually grow. Rather, the team of Ordnance Survey experts who remeasured it for the first time since 1949 were able to do so more accurately because of improvements in technology, and specifically through the use of GPS.

\section{Diane Coyle, Professor of Economics, University of Manchester and Fellow, Office for National Statistics}

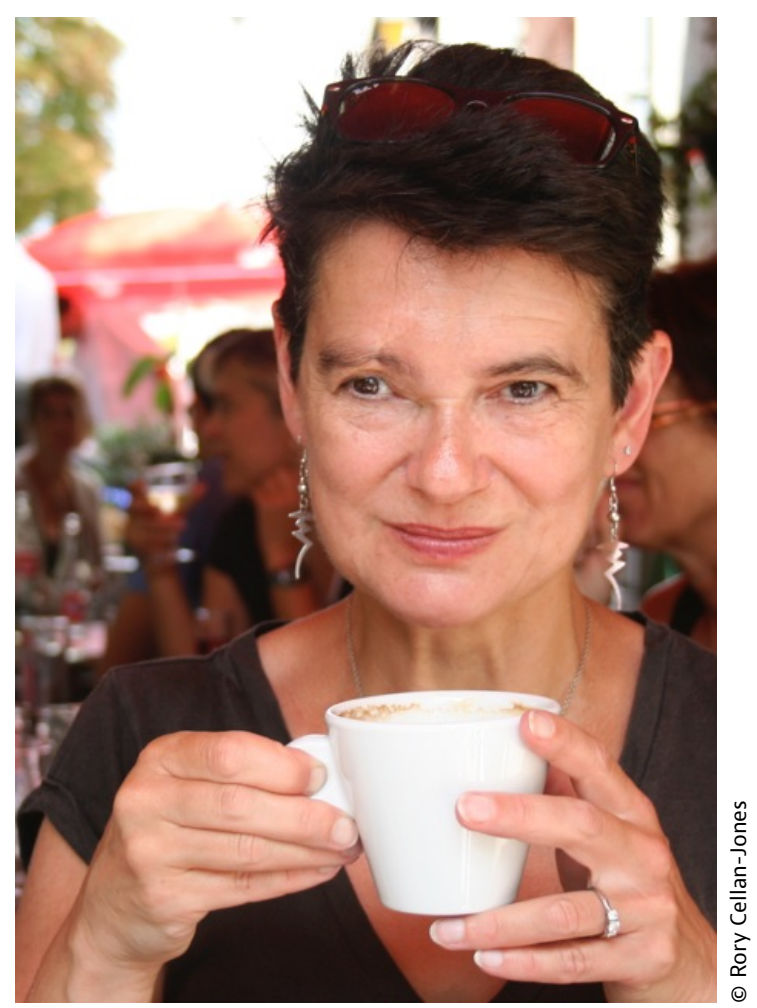

Many people think measuring the size of the economy-the Gross Domestic Product (GDP)-is a task like measuring the height of a mountain. There are errors and revisions, but in principle the experts could find ways to make the measurement more accurate. But in fact, lots of judgements are involved in 
defining and measuring GDP, and over the decades there have been criticisms of some of these. For example, we measure the economy without taking account of the environmental costs of some activities, or overlooking the value of unpaid work in the home.

One response to such criticism is to argue that as these do not have market values, leaving them out is not a problem as long as we remember that GDP is nothing more than a measure of market activity. It is a weak response; after all, government services are counted and there is no market value for them either. Now there is an even more powerful challenge to the way GDP is currently defined and measured because of the way digital activities are changing the economy.

One obvious point is that lots of online activities are free, so also do not have a market price. Those that are funded by advertising are not genuinely "free", as everybody is becoming aware, but even so are hard to value and incorporate into GDP. However, others are the product of voluntary work, including open source software, personal blogs, entertaining videos and so on. At present the statistics treat them just like volunteering at the local school or charity shop, or to cook meals at home. This is starting to seem like quite a large omission.

So too is the rapidly growing phenomenon of the "sharing economy", a loose term describing digital platforms ranging from local time banks or swap schemes, through peer-to-peer financing and freelance employment websites, to giant companies such as Airbnb. These platforms bring together suppliers of a service and consumers, sometimes in a monetary transaction, sometimes in a social relationship. They create value for their users on both sides (because there is always the option of not participating), but it does not always involve a price.

Even when users pay the platform and the supplier a fee, they will be getting an extra non-monetary benefit-for example, finding a more distinctive or cheaper or more convenient place to stay than through a conventional hotel. Economists term this improved matching of supply to consumer tastes the "consumer surplus". This is how much more the consumer values the service than they have had to pay. It is never captured in GDP, which measures transactions at the price paid. But if innovations mean that this consumer surplus is increasing, then it seems that GDP is missing an important phenomenon.

Besides, given the controversy about the conditions of work in the sharing economy, it would be useful to have more statistical insight into it. How many people are actually working in this more contingent way in OECD countries? How do their earnings and conditions actually compare to conventional jobs? Are they content with this way of making a living or only doing it because there is nothing better available? We don't know. These are important questions if we hope the digital transformation will enable an inclusive economy. 
Digital business models in general pose a challenge to the statisticians. For example, there are several sectors of the economy where business has been moving off the high street and online-think of book retailing, travel agency, or banking. As a result, there has been declining investment in commercial real estate, a component of business investment and therefore GDP. So digitisation will in this way have contributed directly to some reduction in GDP, while consumers have enjoyed at least the same service.

In addition, the fact that this is a business model choice means GDP could change if a publisher decides to switch to a subscription based model. Digital goods are often bundled together in packages that change frequently. Determining the price of specific goods is challenging, to say the least. Yet without accurate price indices, it is not possible to calculate the real growth rate of GDP, the single most important gauge of how well the economy is doing. More generally, the information available on all services including the digital sectors is lamentable, given the framework for classifying statistics that was set in the late 1940s, when manufacturing was far more important. We simply have too little information of any kind about the dynamic sectors of the OECD economies.

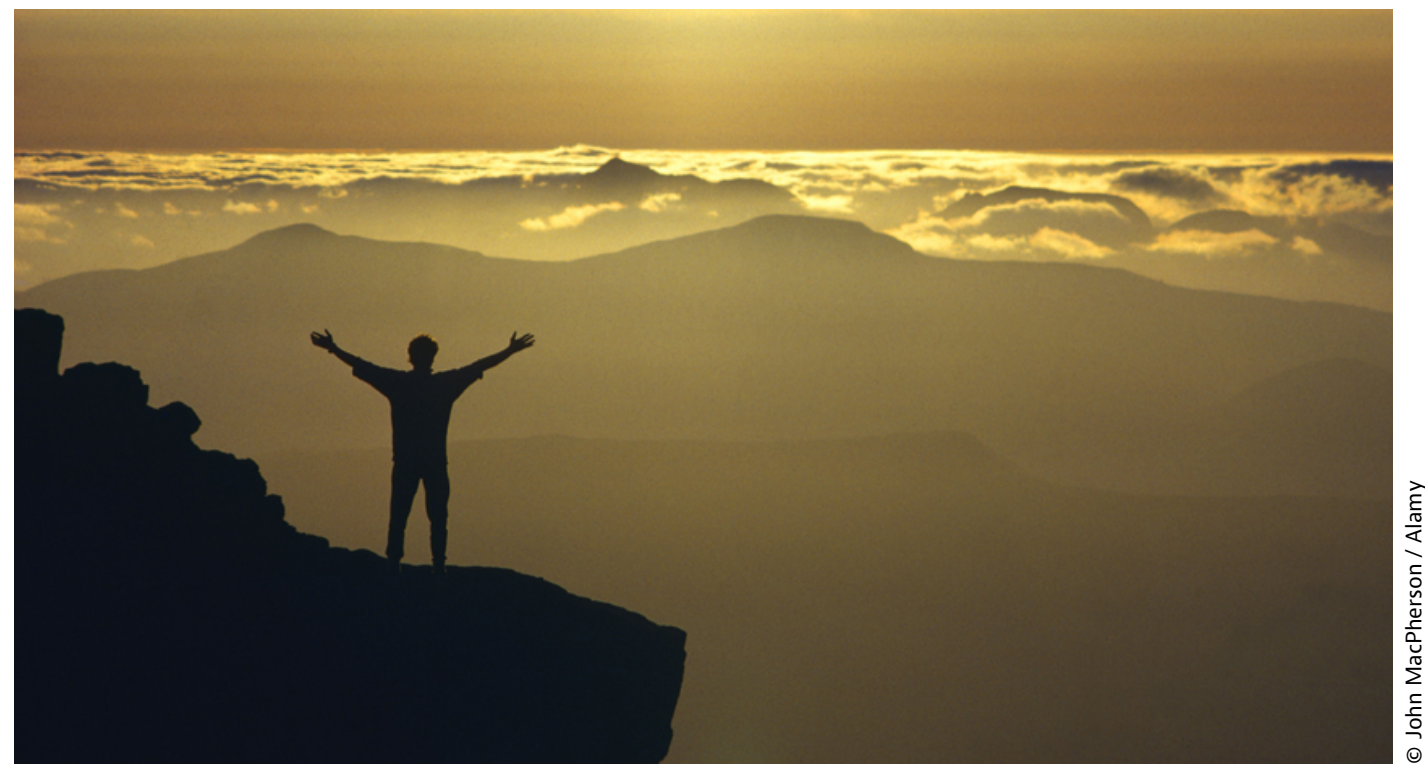

One of the most contentious issues is whether price indices adequately capture the pace of technical progress in many goods. The problem is that the price of an item to consumers, such as a laptop or mobile phone, might not decline but the quality of that item has improved enormously, with more memory, better cameras, faster speeds and so on. Statisticians in OECD countries do make what are called hedonic adjustments for some items in their price indices. However, many in the tech businesses do not think the price adjustments match the pace of technological progress they observe. In the chart below, the scale is logarithmic, 
so it shows the speed of decline in the price of computer processing is still exponential, in line with Moore's Law-based on an observation by Intel cofounder Gordon Moore in 1965, that the density of transistors in integrated circuits (and hence computing power) would roughly double every two years.

If the price index is overstated, real GDP will be understated. This issue is at the heart of the debate among economists about what part of the current slowdown in productivity in OECD economies can be attributed to measurement issues, and remains an open question.

The question of whether the digital transformation is making existing methods of defining and measuring the economy less useful is not just an academic one. Statistics guide policy and allow citizens to hold politicians to account. Independent and reliable official statistics are a public good in democratic, information-based economies. The pace of change in the OECD countries is making the existing statistical framework decreasingly appropriate for measuring the economy and it is therefore hindering the development of policies for higher productivity and growth. Different statistics will not change the current reality, any more than more accurate instruments actually increased the height of Ben Nevis; but they will help shape the future. Statistics are not facts; they are tools.

\section{References}

Coyle, Diane (2015), "Modernising Economic Statistics: why it matters", National Institute Economic Review, November http://www.niesr.ac.uk/sites/default/ files/publications/NIER234Commentary.pdf

Coyle, Diane (2014), "The ups and downs of GDP", OECD Yearbook http:// www.oecd.org/forum/oecdyearbook/the-ups-and-downs-of-gdp.htm

Coyle, Diane (2013), "The cost of mistrust", OECD Yearbook http:// www.oecd.org/forum/the-cost-of-mistrust.htm 